\title{
The MASCC/ISOO mucositis guidelines 2019: the second set of articles and future directions
}

\author{
Sharon Elad ${ }^{1}$ \\ Published online: 12 February 2020 \\ (C) Springer-Verlag GmbH Germany, part of Springer Nature 2020
}

This editorial introduces the second set of articles related to the update of the clinical practice guidelines for mucositis, developed by the Mucositis Study Group of the Multinational Association of Supportive Care in Cancer/International Society of Oral Oncology (MASCC/ISOO). The first set of articles was published in a special section of the July 2019 issue of Supportive Care in Cancer. The July 2019 articles described the methods used [1] and results related to gastrointestinal mucositis [2], as well as other classes of interventions for oral mucositis including anti-inflammatory agents [3], photobiomodulation [4], vitamins, minerals, and nutritional supplements [5], and protocols categorized as basic oral care [6]. Furthermore, an entire paper was dedicated to advances in the understanding of the pathogenesis of mucositis [7].

This issue includes another set of articles that are part of the update for the MASCC/ISOO clinical practice guidelines for the management of mucositis. This set focuses on the following topics: growth factors and cytokines [8], antimicrobials, mucosal coating agents, anesthetics, and analgesics [9], cryotherapy [10], and natural and miscellaneous agents [11]. For each of these topics, the literature was reviewed systematically, and new evidence was merged with the evidence published in the previous guideline update [12]. All the data was used to define the up-to-date level of evidence (LoE) and a guideline category: Recommendation, Suggestion, or No Guideline Possible.

For all four topics, new evidence was identified, including evidence for interventions for which guidelines were established in the previous update. The new evidence resulted in three scenarios: (1) the LoE and the guideline statement remained unchanged; (2) the LoE was enhanced and the guideline statement remained unchanged; (3) reversal of the

Sharon Elad

selad@urmc.rochester.edu

1 Oral Medicine, Eastman Institute for Oral Health, University of Rochester Medical Center, 625 Elmwood Ave,

Rochester, NY 14620, USA guideline statement. In the section presenting Natural and Miscellaneous Agents, evidence for numerous new agents was identified, and 3 new guidelines were established.

Notwithstanding, the guidelines are based on a thorough systematic review of the literature. As such, interventions reported in clinical trials in the scientific literature were included. The guidelines are not a review or a list of the commercially available interventions. We plan to update the guidelines periodically, and new interventions may be included in the future.

Historically the MASCC/ISOO mucositis guidelines offered clinicians an evidence-based tool that presented the weighted-evidence in a coded and standardized manner. This was a necessity during the decades in which the literature was developing and the scientific data were poor. Thus, the MASCC/ISOO guidelines bridged the gap between the need to provide palliation and the wish for an evidence-based efficient therapy. From the first publication of the MASCC mucositis guidelines [13], and including the 1st [14], and 2nd guideline update [12], the methods applied by the MSG were meticulous $[15,16]$. These methods are considered "state-ofthe-art" regarding systematic review methodology and its protocols aligned with statements from leaders of the American Society of Clinical Oncology [17, 18]. Actually, with each guideline update, the methods became stricter. The most recent methods required at least 2 randomized controlled trials (RCTs) to qualify an intervention for a Suggestion type of guideline, and at least one of these RCTs needed to be flawless to reach a Recommendation type of guideline [1]. Although the amount and level of evidence increased dramatically, it is important to recognize that very few interventions reached a Recommendation type of guideline. Furthermore, although the number of RCTs increased, the power of many RCTs was low. Therefore, the need for the clinical practice guidelines remains valid.

The MASCC/ISOO guidelines was established in 2003 and, as mentioned above, is a continuing project. It has progressed simultaneously with the medical community's expectation of high-quality systematic reviews. The 
establishment of the International Prospective Register of Systematic Reviews (PROSPERO) of the UK National Institute for Health Research is an example of a major upgrade that the concept of systematic reviews underwent. PROSPERO was launched in 2011 and follows the model outlined in the PRISMA statement in 2010. With the endorsement of PROSPERO by the Cochrane Collaboration in 2013, PROSPERO became a synonym for the accepted standard in systematic review. The MASCC/ISOO methodology of systematic reviews progressed in parallel, with similar outcomes. The unique feature of the MASCC/ISOO approach to the systematic review is the translation of the evidence into clinical practice guidelines thereby assuring the practicality of the evidence in the clinical setting. While the MASCC/ISOO clinical practice guidelines are not a meta-analysis, the risk bias and the power of each study are considered and conclusions are based on the best available evidence.

The ultimate goal of the MASCC/ISOO guidelines is to improve the health care of cancer patients. To this end, we need to continue working collaboratively. The publication of the mucositis guideline update is an important link in a chain of actions required to fulfill this goal. Dissemination of the new MASCC/ISOO mucositis guidelines update, implementation of the guidelines in the clinical setting, long-term assessment of its outcomes, and identification of impediments for implementations are important future steps in this chain of actions. The MSG recognizes the implementation may not be universal due to regional variation in the availability of the interventions, regulatory and economic considerations, as well as preferences of patients and clinicians.

The MASCC/ISOO mucositis guideline update reflects the tremendous progress in mucositis research over the years. Although the number of interventions supported by strong evidence has increased since the previous update, it seems that the need for palliative interventions for this cancer therapy complication remains unmet and that there are many questions that warrant additional research.

\section{Compliance with ethical standards}

Conflict of interest According to the MASCC Guidelines Policy, employees of commercial entities were not eligible to serve on this MASCC Guidelines Panel. All authors completed a Conflict of Interest Disclosure form and conflicts are disclosed in the guideline's publications. The author discloses no conflict of interest in regards to the subject matter, and consulting to Falk Pharma outside the submitted work.

Disclaimer The Multinational Association of Supportive Care in Cancer and International Society of Oral Oncology (MASCC/ISOO) Mucositis Guidelines are developed to facilitate the evidence-based management of mucositis. However, clinicians should also use their own judgment in making treatment decisions for individual patients. The guideline authors and the MASCC/ISOO do not guarantee or take responsibility for clinical outcomes in individual patients.
These guidelines refer to the use of the agents listed for the specific indication listed (i.e., the prevention or treatment of mucositis or related symptoms).

\section{References}

1. Ranna V, Cheng KKF, Castillo DA, Porcello L, Vaddi A, Lalla RV, Bossi P, Elad S (2019) Development of the MASCC/ISOO clinical practice guidelines for mucositis: an overview of the methods. Support Care Cancer 27:3933-3948

2. Bowen JM, Gibson RJ, Coller JK, Blijlevens N, Bossi P, AlDasooqi N, Bateman EH, Chiang K, de Mooij C, Mayo B, Stringer AM, Tissing W, Wardill HR, van Sebille YZA, Ranna V, Vaddi A, Keefe DM, Lalla RV, Cheng KKF, Elad S (2019) Systematic review of agents for the management of cancer treatment-related gastrointestinal mucositis and clinical practice guidelines. Support Care Cancer 27:4011-4022

3. Ariyawardana A, Cheng KKF, Kandwal A, Tilly V, Al-Azri AR, Galiti D, Chiang K, Vaddi A, Ranna V, Nicolatou-Galitis O, Lalla RV, Bossi P, Elad S (2019) Systematic review of anti-inflammatory agents for the management of oral mucositis in cancer patients and clinical practice guidelines. Support Care Cancer 27:3985-3995

4. Zadik Y, Arany PR, Fregnani ER, Bossi P, Antunes HS, Bensadoun RJ, Gueiros LA, Majorana A, Nair RG, Ranna V, Tissing WJE, Vaddi A, Lubart R, Migliorati CA, Lalla RV, Cheng KKF, Elad S (2019) Systematic review of photobiomodulation for the management of oral mucositis in cancer patients and clinical practice guidelines. Support Care Cancer 27:3969-3983

5. Yarom N, Hovan A, Bossi P, Ariyawardana A, Jensen SB, Gobbo M, Saca-Hazboun H, Kandwal A, Majorana A, Ottaviani G, Pentenero M, Nasr NM, Rouleau T, Lucas AS, Treister NS, Zur E, Ranna V, Vaddi A, Cheng KKF, Barasch A, Lalla RV, Elad S (2019) Systematic review of natural and miscellaneous agents for the management of oral mucositis in cancer patients and clinical practice guidelines-part 1: vitamins, minerals, and nutritional supplements. Support Care Cancer 27:3997-4010

6. Hong CHL, Gueiros LA, Fulton JS, Cheng KKF, Kandwal A, Galiti D, Fall-Dickson JM, Johansen J, Ameringer S, Kataoka T, Weikel D, Eilers J, Ranna V, Vaddi A, Lalla RV, Bossi P, Elad S (2019) Systematic review of basic oral care for the management of oral mucositis in cancer patients and clinical practice guidelines. Support Care Cancer 27:3949-3967

7. Bowen J, Al-Dasooqi N, Bossi P, Wardill H, Van Sebille Y, Al-Azri A, Bateman E, Correa ME, Raber-Durlacher J, Kandwal A, Mayo B, Nair RG, Stringer A, Ten Bohmer K, Thorpe D, Lalla RV, Sonis S, Cheng KKF, Elad S (2019) The pathogenesis of mucositis: updated perspectives and emerging targets. Support Care Cancer 27: 4023-4033

8. Logan RM, Al-Azri AR, Bossi P, Stringer AM, Joy JK, Soga Y, Ranna V, Vaddi A, Raber-Durlacher J, Lalla RV, Cheng KKF, Elad S (2019) Systematic review of growth factors and cytokines for the management of Oral Mucositis in cancer patients and clinical practice guidelines. Support Care Cancer https://doi.org/10.1007/ s00520-019-05170-9

9. Saunders DP, Rouleau T, Cheng KKF, Yarom N, Kandwal A, Joy J, Bektas K, van de Wetering M, Brito-Dellan N, Kataoka T, Chiang K, Ranna V, Vaddi A, Epstein J, Lalla RV, Bossi P, Elad S (2019) Systematic review of antimicrobials, mucosal coating agents, anesthetics, and analgesics for the management of oral mucositis in cancer patients and clinical practice guidelines. Support Care Cancer https://doi.org/10.1007/s00520-019-05181-6

10. Correa MEP, Cheng KKF, Chiang K, Kandwal A, Loprinzi CL, Mori T, Potting C, Rouleau T, Toro JJ, Ranna V, Vaddi A, Peterson DE, Bossi P, Lalla RV, Elad S (2019) Systematic review 
of oral cryotherapy for the management of oral mucositis in cancer patients and clinical practice guidelines. Support Care Cancer https://doi.org/10.1007/s00520-019-05217-x

11. Yarom N, Hovan A, Bossi P, Ariyawardana A, Jensen SB, Gobbo M, Hazboun HI, Kandwal A, Majorana A, Ottaviani G, Pentenero M, Nasr N, Rouleau T, Skripnik Lucas A, Treister NS, Zur E, Ranna V, Vaddi A, Cheng KKF, Barasch A, Lalla RV, Elad S (2019) Systematic review of natural and miscellaneous agents, for the management of oral mucositis in cancer patients and clinical practice guidelines - Part 2: honey, herbal compounds, saliva stimulants/inhibitors, probiotics and miscellaneous agents. Support Care Cancer https://doi.org/10.1007/s00520-019-05256-4

12. Lalla RV, Bowen J, Barasch A, Elting L, Epstein J, Keefe DM, McGuire DB, Migliorati C, Nicolatou-Galitis O, Peterson DE, Raber-Durlacher JE, Sonis ST, Elad S (2014) MASCC/ISOO clinical practice guidelines for the management of mucositis secondary to cancer therapy. Cancer 120:1453-1461

13. Rubenstein EB, Peterson DE, Schubert M, Keefe D, McGuire D, Epstein J, Elting LS, Fox PC, Cooksley C, Sonis ST (2004) Clinical practice guidelines for the prevention and treatment of cancer therapy-induced oral and gastrointestinal mucositis. Cancer 100: 2026-2046
14. Keefe DM, Schubert MM, Elting LS, Sonis ST, Epstein JB, RaberDurlacher JE, Migliorati CA, McGuire DB, Hutchins RD, Peterson DE (2007) Updated clinical practice guidelines for the prevention and treatment of mucositis. Cancer 109:820-831

15. Bowen JM, Elad S, Hutchins RD, Lalla RV (2013) Methodology for the MASCC/ISOO Mucositis clinical practice guidelines update. Support Care Cancer 21:303-308

16. Elad S, Bowen J, Zadik Y, Lalla RV (2013) Development of the MASCC/ISOO clinical practice guidelines for mucositis: considerations underlying the process. Support Care Cancer 21:309-312

17. Hadorn DC, Baker D, Hodges JS, Hicks N (1996) Rating the quality of evidence for clinical practice guidelines. J Clin Epidemiol 49: 749-754

18. Somerfield MR, McCrae RR (2000) Stress and coping research. Methodological challenges, theoretical advances, and clinical applications. Am Psychol 55:620-625

Publisher's note Springer Nature remains neutral with regard to jurisdictional claims in published maps and institutional affiliations. 